\title{
ON A KININ-LIKE SUBSTANCE IN THE NERVOUS TISSUE EXTRACTS TREATED WITH TRYPSIN
}

\author{
Akira Inouye, Kiyoshi Kataoka AND Toshiaki TsuJIOKA* \\ Department of Physiology, Kyoto University, Kyoto, Japan
}

ZETLER and OHNESORGE (1957) have already reported that gut-stimulating activity of substance $\mathrm{P}$ (SP) in a crude extract of mouse brain prepared by the usual drastic extraction (i.e. boiling with water of $\mathrm{pH} \mathrm{3-4)} \mathrm{is} \mathrm{inactivated} \mathrm{on}$ incubation with trypsin, while that extracted by a rather mild method (i.e. about $70 \%$ ethanol extraction at room temperature) is not apparently destroyed by trypsin, the activity remaining after incubation being originated from a substance produced by trypsin. In our laboratory, their results could be also confirmed on the crude extracts of bovine dorsal root and guinea-pig brain (TsUJIOKA 1958). In further experiments it was found that such a gut-stimulating activity after trypsin treatment can be ascribed to a component (component $\mathrm{T}$ ) which resembles kinin compounds such as bradykinin (RochA e SILVA et al. 1949) or plasmakinin (LEwIS, 1958) in its physiological and chemical properties. This paper is chiefly concerned with this respect.

\section{MATERIALS AND METHODS}

The methods and materials used are quite similar to those employed by TsuлIoKA (1958).

Materials: Bovine spinal cords were obtained from a slaughter house which were stored in a Dewer bottle kept below $4^{\circ} \mathrm{C}$ immediately after killing the animals. Their dorsal and ventral roots were excised as quickly as possible in the cold and freed from blood vessels macroscopically recognized. When large amount of materials desired, 5-10 spinal cords were dissected into dorsal and ventral halves with their attached roots and subjected to the following extraction.

Guinea-pig brain, killed by a blow on head, was also used for preparing a whole brain extract. In such a case, its cerebellum was omitted.

As stated below, small intestine of guinea-pig or rabbit was found to provide considerable amount of component $\mathrm{T}$ as well as substance P. In some observations, therefore, active substances prepared from these materials were employed.

Extraction: According to ZETLER and OHNESORge, a- and b-extraction methods were applied, only difference being that the latter was applied to an aliquot of fresh material without previous repeated a-extraction used in the original one and its activity was compared with a-extract prepared from the other aliquot.

Received for publication December 29, 1960

* 井上章, 片岡喜由, 过岡俊明 
Large scale extraction was carried out after EulER's method (1942) for preparing substance $\mathrm{P}$ as shown in the diagram presented in the following section with combination with the method of preparing crude bradykinin employed by ANDRADE and Rocha e Silva (1957).

Biological assay: Isolated guinea-pig ileum (about $1 \mathrm{~cm}$ long) was suspended in $5 \mathrm{ml}$ organ bath containing aerated Tyrode solution at $30^{\circ} \mathrm{C}$, its $\mathrm{pH}$ being usually adjusted to 6.8 with phosphate buffer. Atropine, pyribenzamin and tryptamin or 5HT were usually added to the reservoir in concentration of at least $10^{-6}$ for the former two, $10^{-4}$ or more for the latter. Amount of test solution added to the bath was usually $0.1-0.5 \mathrm{ml}$. To examine the effect of some drugs on the action of substance $\mathrm{P}$ or component $\mathrm{T}(\mathrm{CT})$, these drugs were added to the bath about 10 minutes prior to SP or CT administration, their concentration being given as the final concentration in the bath fluid and referred to the salt.

D-enzyme solution: According to UMRATH (1953), $1 \mathrm{ml}$ of bicarbonate free Ringer solution was added to $1 \mathrm{~g}$ of the fresh bovine dorsal root. After grinding in a mortar, the solution was centrifuged at 3,200 r.p.m. and used as an enzyme solution (D-enzyme) which was found to inactivate about $60-95 \%$ of SP activity on incubation for 4 hours. The operations were carried out as aseptically as possible. Trypsin or chymostrypsin (Mochida's preparation) was also used, its being dissolved in the Tyrode's fluid to give a solution of $3 \mathrm{mg} / \mathrm{ml}$.

Incubation: The enzyme solution was added to the test extract solution in its $1 / 10$, volume. After incubation at $37^{\circ} \mathrm{C}$ (for 4 hours for D-enzyme and for 30 minutes for proteinases), the mixture was boiled for a few minutes to stop the enzyme action, and also to eliminate the effect of enzyme on the test preparations. In some cases, however, the procedure of trypsin desensitization is necessary to eliminate its gut-stimulating activity (Rocha e Silva, 1940). For control experiments the test extract, boiled immediately after adding enzyme solution and incubated, was used, which was almost always proved to have an activity identical with that of the untreated original extract.

\section{RESULTS}

I. Experiments on the crude extracts: As shown in FIG. 1, a- as well as b-extract have the gut-stimulating action on the guinea-pig's isolated intestine, both activity being blocked by prior administration of high dose of SP to the organ bath, a fact which indicates that an active component present in these extracts is SP or a SP-like substance. After incubation with trypsin, the activity of b-extract was completely destroyed, whereas that of a-extract still remained. Moreover, the desensitization of the test preparation to SP could not abolish the activity of trypsin treated a-extract completely. Thus the results reported by ZetLer and OHNesorge could be confirmed. When a mixture of a- and bextract was incubated with trypsin, its activity was also reduced to an extent which could be expected by complete inactivation of the gut-stimulating action of bextract contained in it (FIG. 1). Hence, it can be concluded that a-extract does not contain a trypsin-inhibiting factor which protect SP from enzymatic 


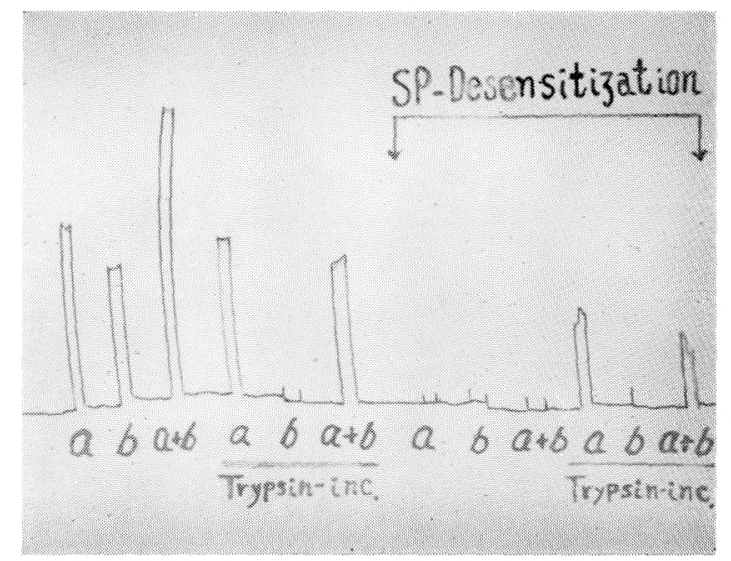

FIG. 1. Effect of incubation with trypsin on a- and b-extract as well as on their mixture. Isolated guinea-pig ileum. Bath volume $5 \mathrm{ml}$.

a: a-extract.

b: b-extract.

$a+b$ : mixture of control $a-$ and $b$-extract, its quantity applied being equivalent to sum of the above two.

In the second series (SP-desensitization), high dose of SP was added to the bath.

In the underlined part, each test sample was applied after incubation with trypsin.

inactivation.

The gut-stimulating action of trypsin-treated a-extract is also destroyed neither by further incubation with trypsin nor by D-enzyme solution and not potentiated by LSD. As reported previously (TSUJIOKA, 1958), however, the action of SP in the crude extract is inactivated by incubation with crude saline extract of bovine dorsal roots (D-enzyme solution), such an inactivation of bextract is inhibited to some extent by strychnine, LSD and monoiodoacetate, and LSD potentiate the gut-stimulating action of b-extract, while these drugs barely affect the gut-stimulating action of a-extract or its inactivation by D-enzyme solution (see FIG. 2).

It is apparent, therefore, that the gut-stimulating activity of a-extract remaining after trypsin-treatment should be ascribed to a newly produced substance, which is termed as "Component T (CT)" throughout in this paper.

II. Extraction of Component T: Pooled bovine dorsal cords (0.5-1.0 kg) freed from attached blood vessels were extracted by 3 volumes of $70 \%$ ethanol at room temperature (a-extraction). After concentrated in vacuo and finally freeze-dried, the residue was dissolved into distilled water ( $1 \mathrm{ml} / 10 \mathrm{~g}$ tissue), the supernatant separated by centrifugation (4,000 r.p.m.) was divided into two portions of equal amount, the one (FA 1) was directly subjected to Euler's method of isolating SP, the other being treated in the same manner after incubation 


\section{DIAGRAM I}

Extraction of Substance $\mathrm{P}$ and Component $\mathrm{T}$.

Diagram.

\begin{tabular}{c} 
Bovine Spinal Cords \\
$0.5-1.0 \mathrm{~kg}$ \\
\hline
\end{tabular}

Boiling with 2 vol. distilled water at

Extracted by 3 vol. $70 \%$ ethanol:

$\mathrm{pH} 4.0$; concentrated in vacuo $(25 \mathrm{C})$,

$\Leftarrow$ concentrated in vacuo $\left(25^{\circ} \mathrm{C}\right)$ after $\Rightarrow$

2 vol. ethanol added and filtered after

filtration; divided to two portions

standing overnight at $4-6^{\circ} \mathrm{C}$

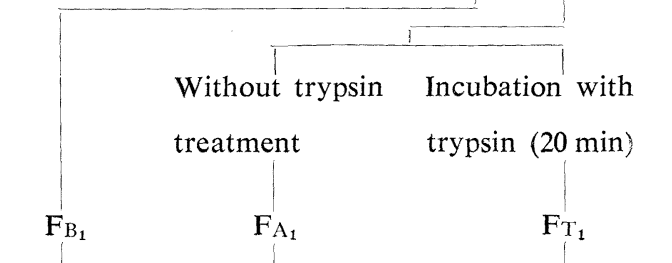

Concentrated in vacuo; 3 vol. ethanol added; filtered after standing overnight

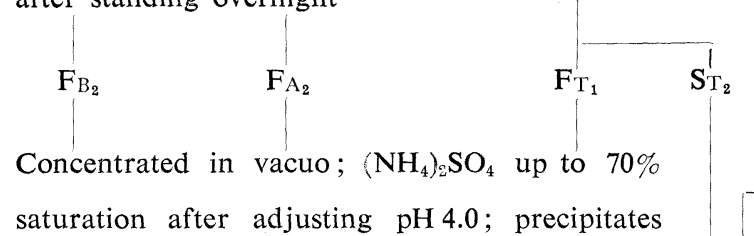

2 vol. hot ethanol added and

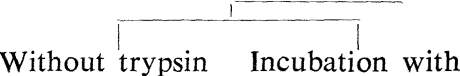

treatment trypin

boiled for $10 \mathrm{~min}$; concentrated in vacuo to dryness saturation after adjusting $\mathrm{pH} 4.0$; precipitates setes separated by centrifugation after standing overnight

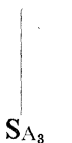

Dissolved in $70 \%$ ethanol ; 3 vol. acetone added; precipitates washed with aceton and dryed
SP
SPA
$\mathrm{SP}_{\mathrm{T}} \quad \mathrm{AT}_{\mathrm{T}} \mathrm{CT} \quad \mathrm{SP}_{\mathrm{A}}^{\prime}$
$\mathbf{S P}_{\mathrm{T}}^{\prime}$

with trypsin $(20 \mathrm{mg} / 10 \mathrm{~g}$ tissue) for 30 minutes (FT 1). Standard SP preparation was prepared by Euler's method. The extraction procedure is shown in the following diagram.

The gut-stimulating activity of each fraction was examined on guinea-pig's isolated intestine. Three series of such a extraction experiments were carried out, their results being summarized in TABLE 1 . These results indicate clearly that the gut-stimulating component produced by trypsin-treatment can not be 
SP

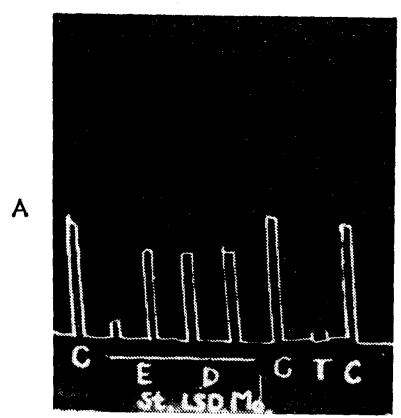

B

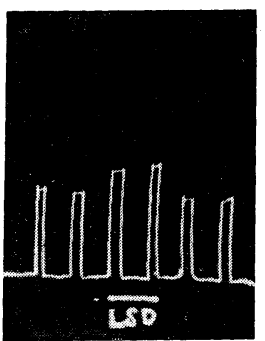

FA
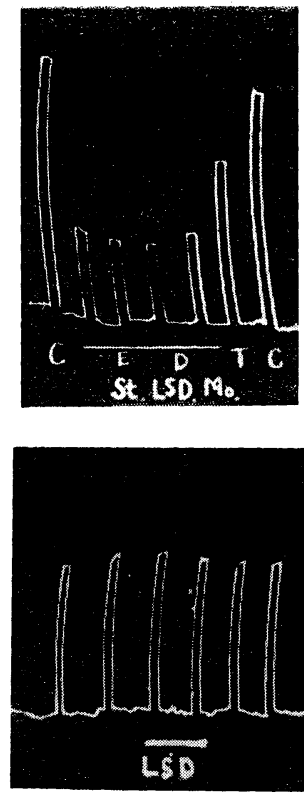

$S P^{\prime} T$
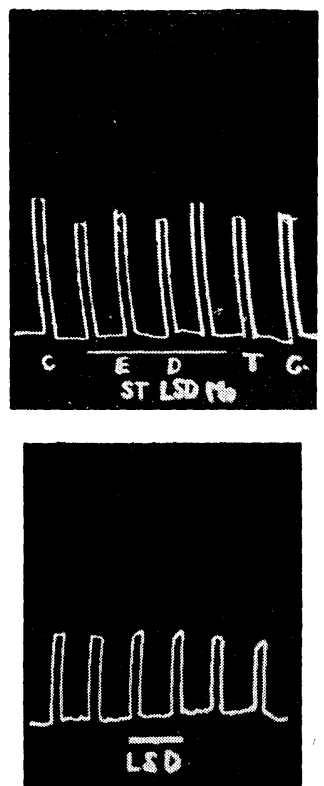

FIG. 2. Effect of incubation with D-enzyme solution as well as with trypsin on the gut-stimulating activity of some fractions.

SP, FA, SP'T: See the flowing diagram.

A C: Control response of each fraction.

Underline indicates that samples applied was incubated with D-enzyme solution in the absence or presence of strychnine $\langle\mathbf{S t}\rangle$, lysergic acid diethylamide (LSD) and monoiodoacetate (Mo). Note that these added drugs inhibit only inactivation of SP fraction.

$\mathrm{T}$ : Samples incubated with trypsin.

B LSD potentiation.

Underline indicates the presence of LSD $\left(10^{-8}\right)$ in the bath fluid.

found after salting out procedure. Hence the precipitate obtained by ethanol treatment (ST 2) was extracted by hot ethanol and subjected to the extraction method for preparing crude bradykinin (T-extraction). The precipitate obtained by dry ether addition (CT) is found to be gut-stimulating, its activity being destroyed neither by trypsin nor by incubation with D-enzyme solution and also unaffected by LSD or not abolished by desensitization of the test preparation to SP (FIG. 2). These characteristics are the very ones which are observed on the crude a-extract after trypsin treatment. Moreover, the contraction produced by CT is far slower than that caused by SP and appears to have a close resemblance to the contractions produced by kinin compounds (LEWIS, 1958). Hence it was attempted to apply the isolation method of crude kinin to a-extract of bovine spinal cord (see the above diagram) and found that the trypsin treated a-extract provides a gut-stimulating component whose characteristics are quite similar to 
TABLE 1

Comparison of the gut-stimulating activity of each fraction.

\begin{tabular}{|c|c|c|c|c|c|c|c|c|c|}
\hline & & \multirow{2}{*}{ Control } & \multicolumn{5}{|c|}{ after incubation with } & \multirow{2}{*}{$\begin{array}{l}\text { after SP } \\
\text { desensi- } \\
\text { tization }\end{array}$} & \multirow{2}{*}{$\begin{array}{l}\text { LSD } \\
\text { potenti- } \\
\text { ation }\end{array}$} \\
\hline & & & Trypsin & $\begin{array}{l}\text { D-enzyme } \\
\text { alone }\end{array}$ & $\begin{array}{l}\text { D-enzyme } \\
+ \text { strychnine }\end{array}$ & $\begin{array}{l}\text { D-enzyme } \\
+ \text { LSD }\end{array}$ & $\begin{array}{c}\text { D-enzyme } \\
+ \text { monoi. }\end{array}$ & & \\
\hline \multirow{3}{*}{$b$} & $\mathrm{~F}_{\mathrm{B}_{1}}$ & + & 0 & 0 & + & + & + & 0 & + \\
\hline & $\mathrm{S}_{\mathrm{B}_{3}}$ & $H$ & 0 & 0 & + & + & $H$ & 0 & + \\
\hline & SP & H & 0 & 0 & + & + & $H$ & 0 & + \\
\hline \multirow{4}{*}{$\mathrm{a}$} & $\mathrm{F}_{\mathrm{A}_{1}}$ & $H$ & $H$ & $\downarrow$ & $\downarrow$ & $\downarrow$ & $\downarrow$ & 0 & - \\
\hline & $\mathrm{F}_{\mathrm{A}_{2}}$ & + & + & $\downarrow$ & $\downarrow$ & $\downarrow$ & $\downarrow$ & 0 & 1 \\
\hline & $\mathrm{S}_{\mathrm{A}_{3}}$ & + & 0 & $\downarrow$ & + & + & + & 0 & 1 \\
\hline & $\mathrm{SP}_{\mathrm{A}}$ & $H$ & 0 & $\downarrow$ & + & + & + & 0 & + \\
\hline \multirow{4}{*}{$\mathbf{T}$} & $\mathrm{F}_{\mathrm{T}_{1}}$ & + & + & + & + & + & + & $(+)$ & - \\
\hline & $\mathrm{F}_{\mathrm{T}_{2}}$ & \pm & \pm & \pm & \pm & \pm & \pm & \pm & / \\
\hline & $\mathbf{S}_{\mathrm{T}_{3}}$ & 0 & 0 & 0 & 0 & 0 & 0 & 0 & 1 \\
\hline & $\mathrm{SP}_{\mathrm{T}}$ & 0 & 0 & 0 & 0 & 0 & 0 & 0 & 1 \\
\hline & $\mathbf{A}_{T}$ & 0 & 0 & 0 & 0 & 0 & 0 & 0 & - \\
\hline & $\mathrm{C}_{\mathrm{T}}$ & $(+)$ & $(+)$ & $(+)$ & $(+)$ & $(+)$ & $(+)$ & $(+)$ & - \\
\hline & $\mathbf{S P}_{\mathrm{T}}^{\prime}$ & $(+)$ & $(+)$ & $(+)$ & $(+)$ & $(+)$ & $(+)$ & $(+)$ & - \\
\hline & $\mathrm{SP}_{\mathrm{A}}^{\prime}$ & $H$ & H & $\downarrow$ & $\downarrow$ & $\downarrow$ & $\downarrow$ & 0 & - \\
\hline & & $\begin{array}{c}H: \mathrm{St} \\
+: \mathrm{M} \\
\pm: \mathrm{Sl} \\
0: \mathrm{In} \\
\downarrow: \mathrm{D} \\
\text { * In the } \\
+: \mathrm{E} \\
-: \mathrm{In} \\
/: \mathrm{N}\end{array}$ & $\begin{array}{l}\text { ikingly a } \\
\text { oderately } \\
\text { ghtly acti } \\
\text { active } \\
\text { pressant } \\
\text { case of th } \\
\text { fective. } \\
\text { effective. } \\
\text { t tested. }\end{array}$ & $\begin{array}{l}\text { active. } \\
\text { active. } \\
\text { tive. } \\
\text { he LSD pot }\end{array}$ & tenciation, & & & & \\
\hline
\end{tabular}

those of the crude a-extract treated with trypsin, while no gut-stimulating activity can be obtained from the crude a-extract without trypsin treatment (TABLE 1 and FIG. 2).

The former gut-stimulating activity is not completely disappeared after the desensitization of the test preparation to SP, and hence it can be concluded that the activity of the fraction CT or SP'T in the diagram is that found in the crude a-extract of ZETLER and OHNESORGE after trypsin treatment (component $T$ ) and not due to an artefact component produced during T-extraction method. Thus it was proved that the component $\mathrm{T}$ could be extracted by the same method as that of preparing crude kinin compounds.

III. Some physiological properties of component T: A comparison was made of the active component $\mathrm{T}$ (CT) isolated from an incubated mixture of crude a-extract of dorsal root and trypsin by the method stated above with a standard preparation of SP. The results shown in FIG. 3 indicate that the response of 
guinea-pigs ileum to component $\mathrm{T}$ is a slow contraction, proceeded by a short latency, which is quite similar to that caused by plasma kinin, but different from the more rapid response of SP. The experiments on the hen's rectal caecum and rat's uterus and colon also revealed the former is more sensitive to SP than to CT while the latter shows the reverse (FIG. 3). When administered intravenously to the atropinized rabbit, CT shows a hypotensive effect as SP and plasma kinin, but the depressor action of the former nearly equipotent to SP in the gut-stimulating action is less pronounced than that of SP. These facts suggest the similarity in the response of these tissues to both plasma kinin and CT and the difference from that of SP (PERnow \& Rocha e Silva, 1955; Lewis, 1958). In a few observations on denervated rabbit ears after HeLlawer and UMrath (1948), intracutaneas injection of CT solution causes distinct capillary dilatation lasting up about 20 min., which is quite similar to UMRATH's "sensible Erregungssubstanz" or SP (TSUJIOKA, 1958).

A

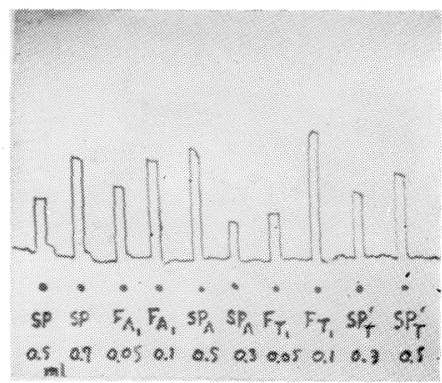

B

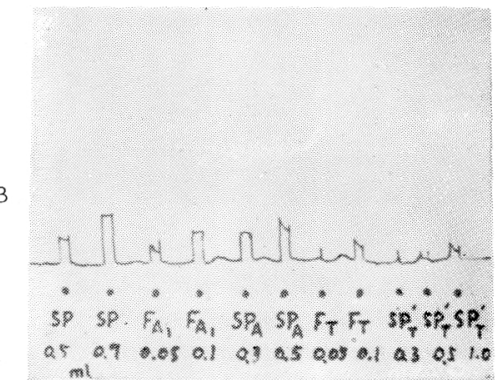

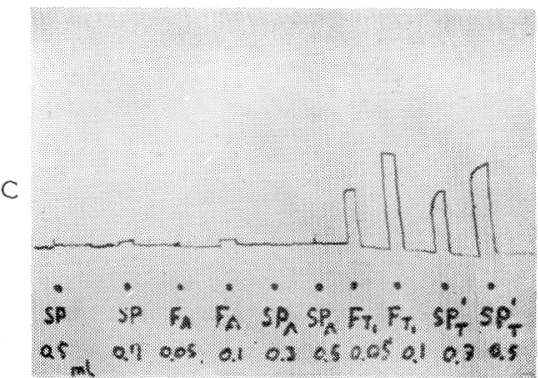

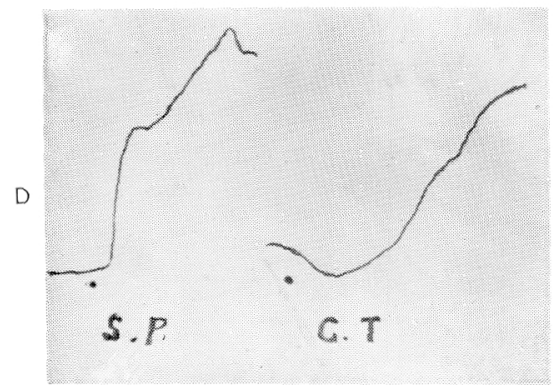

FIG. 3. Discriminative tests en the SP and CT.

A : Guinea-pig's ileum.

B : Hen's rectal caecum.

C: Rat's uterus.

$\mathrm{SP}, \mathrm{CT}$ etc. represents the fraction indicated in the flowing diagram, the numerals attached to them being their quantity applied in $\mathrm{ml}$. In $\mathrm{B}$ and $\mathrm{C}$, the quantity of each fraction is nearly equivalent to each other in the response of guinea-pig ileum.

D: Mode of contraction of SP and CT. At the dot indicated, each sample was administered. Note the longer latency and slower rising phase in the contraction of $\mathrm{CT}$. 
TABLE 2

Relative amount of component $\mathrm{T}$, Substance $\mathrm{P}$ and plasma kinin related to their activity on the guinea-pig's ileum nearly equivalent to each other.

\begin{tabular}{llcc}
\hline & CT & SP & PK* \\
Guinea-pig's ileum & 1 & 1 & 1 \\
Rat's colon & 3 & 1 & 3.4 \\
Rat's uterus & 0.6 & 10 & 0.4 \\
Hen's rectal caecum & 3 & 1 & - \\
\hline
\end{tabular}

* Calculated from Lewis's results.

To distinguish these active principles from one another "the discrimination test" (GADDUM, 1955; GoMES, 1955) is available; a quantitative comparison of effects of these substances on above mentioned test preparations gives the following value (average of three experiments each). 'This TABLE 2 shows clearly that within the limits of experimental error the sensitivity of these preparations to CT varies nearly in parallel with that of plasma kinin reported by LEWIS (1958), whereas that to SP shows large discrepancies. From the results described above, it can be safely said that CT is very similar to, if not entirely identical with, plasma kinin and hence bradykinin (LEWIS, 1958) but quite different from the substance $\mathrm{P}$ in its physiological action.

$I V$. Some chemical properties of component $T$ : The activity of the component $\mathrm{T}$ was not affected by boiling for 1 hour in neutral or acid $(\mathrm{N} \mathrm{HCl}$ or $\mathrm{H}_{2} \mathrm{SO}_{4}$ ) solution, but destroyed by boiling only for several minutes in $0.1 \mathrm{~N}$ $\mathrm{NaOH}$. It was not inactivated when incubated with trypsin or D-enzyme solution for several hours, but destroyed by chymotrypsin (for 30 minutes or longer).

When a-extract of guinea-pig's dorsal cord was incubated with D-enzyme solution, its gut-stimulating activity under atropinization, antihistaminization, and 5HT-desensitization reduced with time of incubation. It can be attributed to decomposition of SP by D-enzyme as stated by TsuJIOKA, the activity remaining 4 hours or more after incubation was found, however, not to be lost by SPdesensitization. An example of such results was illustrated in FIG. 4. As shown in this figure, such a gut-stimulating activity observed after SP desensitization was rather increased with incubation period. Consequently, an incomplete inactivation of SP in the a-extract by D-enzyme solution is only apparent, and a component newly formed by action of D-enzyme solution is responsible for the remaining activity. On the other hand, the gut-stimulating action of the component $\mathrm{T}$ was barely affected by incubation with D-enzyme solution. Accordingly, it seems highly probable that a newly formed component is the component $T$. It might be said, therefore, that the CT activity was obtained from a-extract not only by trypsin but also by D-enzyme solution. The reason why much longer time was needed ( 4 hours or more) and the activity obtained was much less pronounced on incubation with the latter would be ascribed to the amount of 


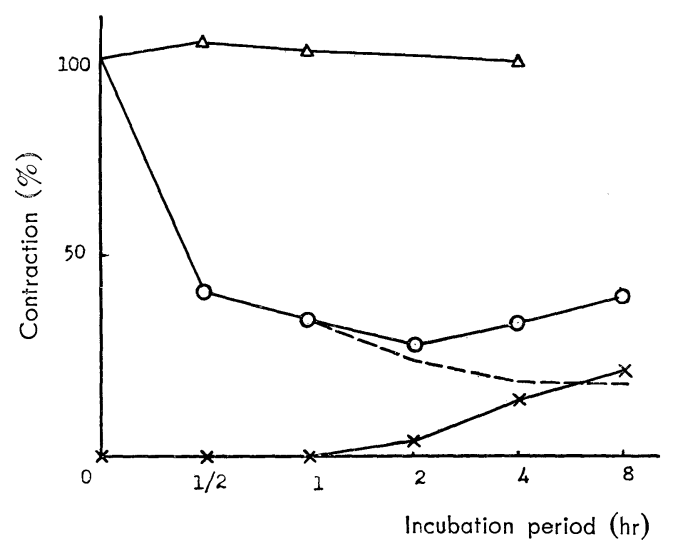

FIG. 4. Effects of D-enzyme solution on a-extract and on Component T. Abscissae: Incubation time in hours. At time 0, sample was boiled immediately after the addition of enzyme solution, which was used as the control response.

Ordinates: Contraction height in per cent of control response.

$O$ : Contraction of a-extract (crude extract of Substance P).

$X$ : Contraction of a-extract after substance $P$ desensitization.

Dotted line represents the net response of Substance $\mathrm{P}$ estimated by substrating the latter from the former.

$\triangle$ : Contraction of Component $T$.

an enzyme or enzymes in the enzyme solution responsible for its formation and/or to the conditions of incubation.

The CT activity was lost when its solution was dialysed against saline for 24 hours in the cold $\left(4^{\circ} \mathrm{C}\right)$, while it was not precipitated by $20-70 \%$ saturation of ammonium sulphate. Our CT fraction is far from pure one and so positive nynhidrin and biuret reaction of its relatively concentrated solution would provide no clue as to its chemical nature. But results stated above indicate that the component $\mathrm{T}$ is with high probability of polypeptide nature as substance $\mathrm{P}$ or kinin compounds.

Because of its similarity to kinin compounds, fractionation by ammonium sulphate was applied to the a-extract, the starting material of CT preparation, to separate its mother substance which is supposed to be pseudoglobulin. But it failed even with $70 \%$ saturation to obtain sufficient precipitate to treat with trypsin. On the other hand, considerable amount of precipitate could be obtained from the b-extract by such a salting-out method (70\%), from which SP activity could be recovered. The reason why a-extract cannot cause precipitation is not clear. When a-extract was dialysed for 24 hours, the CT activity could not be obtained from the solution remaining inside the dialysator bag with trypsin treatment, while the outside solution could provide the CT activity. Hence a mother substance or substances of the $\mathrm{T}$ component is dialysable and appear to 
be of small molecular weight even if they are polypeptides.

$V$. Distribution of a substance or substances providing the component $T$ with trypsin treatment: A question as to whether such a plain muscle stimulating action (CT activity) is obtained only from the extract of brain or spinal cord was not examined by the previous workers. As illustrated in Fig. 5, trypsintreated extract of bovine ventral cord was also gut-stimulating, but its activity was considerably lower than that of dorsal cord when referred to the same weight of the original wet tissues. It was also proved that the extract of guinea-pig cerebellum which had low SP activity, provided low CT activity, while its whole brain extract showed much higher activity of CT as well as SP. Furthermore, the CT fraction prepared from rabbits' skeletal (gastrocnemius) and plain (small intestine) muscles by the similar procedure was gut-stimulating, but the intestine which had high SP content showed much higher CT activity. The activity of both principles found were compared in the TABLE 3, which suggests that CT activity obtained by trypsin treatment runs, roughly speaking, parallel to that of SP. If the component $\mathrm{T}$ is originated from contamination of blood (such as by plasma kinin formation), the skeletal muscle extracts would be rather more active than nervous tissue extracts. Moreover, amount of CT obtained from the ventral cord would be also not necessarily lower than that of dorsal cord. It might be said, therefore, that a precursor (or precursors) of the component $T$ is not derived from blood contaminants, its distribution being related to that of SP to some extent, if not so direct and complete one, and richer in some special region of central nervous system (e.g. dorsal root).

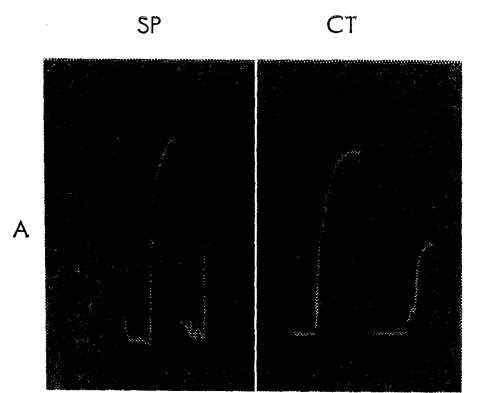

FIG. 5. Comparison of SP and CT activities in some tissues of rabbit. The samples applied in each set of paired responses were obtained

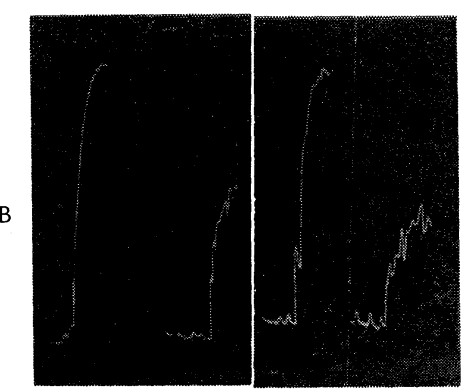
from the same tissue weight to compare their potency directly to each other.

A : Dorsal (left) and ventral (right) cord.

B : Whole brain (left) and cerebellum (right). 
TABLE 3

Distribution of component $\mathrm{T}$ forming power in various tissues of rabbit.

\begin{tabular}{lcc}
\hline & Substance P & Component T \\
Whole brain & 5.0 & 7.5 \\
Cerebellum & 18.0 & 20.8 \\
$\quad$ (Ratio) & $(3.6)$ & $(2.8)$ \\
Dorsal cord & 7.5 & 11.7 \\
Ventral cord & 25.0 & 37.5 \\
$\quad$ (Ratio) & $(3.4)$ & $(3.2)$ \\
Smooth muscle & 1.0 & 4.5 \\
(small intestine) & & 47.0 \\
Striated muscle & & \\
(gastro cnemius) & 33.3 & $(10.4)$ \\
\hline
\end{tabular}

Activity of Component $T$ and Substance $P$ is represented as relative amount of tissues of equal activity with that of control response produced by the standard preparation of Substance P, and the component of smooth muscle for SP activity was taken as unit. The values given above were averages obtained from three series of observations.

$V I$. Effect of some drugs on the gut-stimulating action of component $T$ and substance $P$ : Cocain in the concentration of $2 \times 10^{-7}$, which inhibits gutstimulating action of nicotine nearly completely, shows hardly any effect on the CT and SP activity, whereas in much higher concentration such as $2 \times 10^{-5}$, there was often obtained an slightly increased sensitivity of test preparation to both $\mathrm{SP}$ and CT.

Tetraethylammonium bromide (TEA) in the concentration up to $2 \times 10^{-6}$ did not inhibit the activity of SP and CT. Since the higher concentration of TEA was gut-stimulating by itself, it was impossible to study the effect of TEA of high doses. In one observation, however, TEA of $2 \times 10^{-5}$ depressed the action of SP and CT.

Hexamethonium bromide $\left(\mathrm{C}_{6}\right)$ in the concentration of $2 \times 10^{-5}$, which could nearly completely depress the stimulating action of nicotine, caused no reduction in the action of SP, while $\mathrm{C}_{6}$ of $2 \times 10^{-5}$ or more slightly reduced gut-stimulating action of $\mathrm{CT}$, though no depressant effect of $\mathrm{C}_{6}$ was observed up to $5 \times 10^{-6}$ at least.

Morphine sulphate up to the concentration of $2 \times 10^{-4}$ showed no remarkable effects on the action of SP and CT.

These results with respect to the action of substance $P$ are nearly identical with those reported by Pernow (1953), its properties being similar to that of histamine.

GABA was reported to have antagonizing effects on the gut-stimulating action of acetylcholine (Ach), nicotine and 5-hydroxytryptamine (5HT) but not on those of histamine and $\mathrm{BaCl}_{2}$ (HobBiger, 1958; INOUYE et al., 1960) and such anti-Ach and anti-nicotine action of GABA was found to disappear with 
5-HT-desensitization (INOUYE et al., 1960). In this experiment it could be proved by the similar method used by the previous workers that not only GABA in the higher concentration of $10^{-4}$ exerted hardly any effect on the action of SP and CT, but also its anti-nicotine and anti-5HT action was not affected by prior administration of high dose of SP (SP-desensitization). Desensitization experiment with high dose of CT was scarcely performed because of its relatively longlasting stimulant effect. But it seems highly probable from some observations, that large dose of this substance does not affect anti-nicotine or anti-5HT action of GABA.

According to TsuchiYa (1958), $\varepsilon$-amino-n-caproic acid (EACA) could inhibit powerfully the plasmin contraction of guinea-pig ileum, which he ascribed to a kinin-like compound produced by enzymatic action of plasmin on fibrinogen, while GABA had not such an inhibitory action. Hence the effect of EACA was also examined and found to be not inhibitory on the CT activity. He also described that venadryl, an antihistaminic, depressed the plasmin contraction. These facts seem to indicate that the gut-stimulating action of SP and CT are not related to the receptors or pathway via which the action of 5HT or GABA is displayed, their being rather akin to that of histamine in its pharmacological properties. But pyribenzamine, an antihistaminic, by which the pharmacological action of GABA was not affected, showed the depressant effect on CT only in much higher concentration than on histamine, while the action of SP was affected

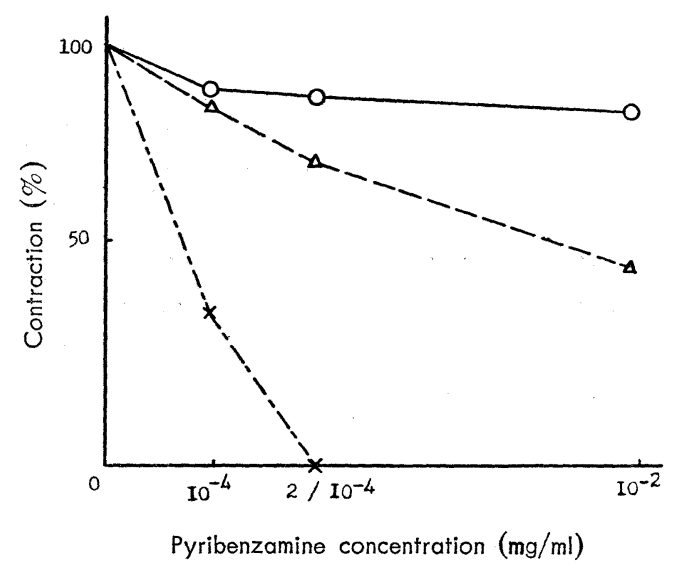

FrG. 6. Effect of antihistaminization (pyribenzamine) on the response to Substance $\mathbf{P}$ and Component $\mathrm{T}$ of guinea-pig ileum.

Abscissae: concentration of pyribenzamine in the bath fluid.

Ordinates: contraction height in per cent of the control response.

$O$ : Contraction of Substance P.

$\triangle$ : Contraction of Component $\mathrm{T}$.

$x$ : Contraction of histamine.

The control response of each substance is nearly equivalent to each other. 


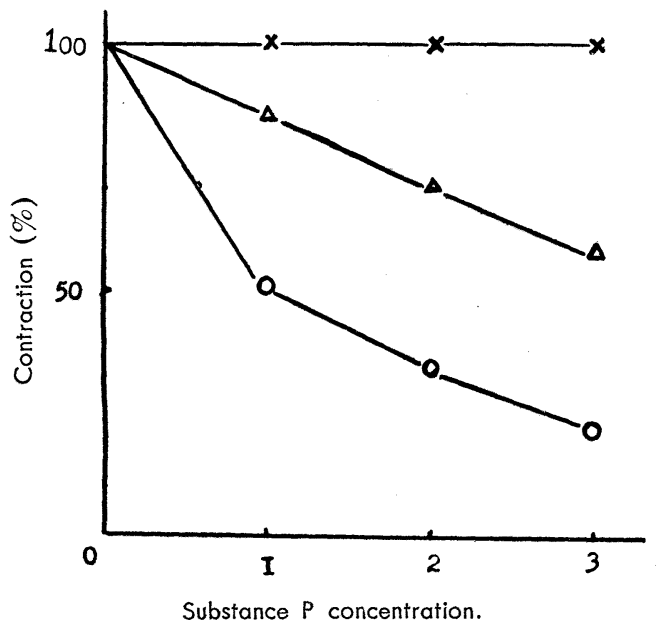

FIG. 7. Effect of desensitization to substance $\mathbf{P}$ on the response to Component $\mathrm{T}$ of guinea-pig ileum, Substance $\mathrm{P}$ and histamine being applied as the control.

Abscissae: Relative concentration of Substance $\mathbf{P}$ in the bath.

Ordinates: Contraction height in percent of control response.

$x$ : Contraction of histamine.

$\Delta$ : Contraction of Component $\mathrm{T}$.

$O$ : Contraction of Substance P.

The control response of each substance is nearly equivalent to each other.

by far more higher dose of pyribenzamine (FIG. 6). Changing doses of SP administered prior to application of CT, SP or histamine, effect of SP desensitization on the nearly equipotent activity of these gut-stimulants was compared. The typical result was illustrated in FIG. 7, which shows that the amount of SP which desensitizes the test preparation nearly completely against the control activity of SP exerts slighter depressant effect on that of CT, much higher dose of SP being required to obtain an obvious reduction in its response to CT. On the other hand the action of histamine was barely affected even by much higher dose of SP.

It might be concluded from these results, therefore, that the gut-stimulating activity of $C^{\prime} \Gamma$ is considerably similar to, but different from that of histamine or of SP from the pharmacological point of view.

\section{DISCUSSION}

Investigations on substance $\mathrm{P}$ in the neuronal tissues have been already reported by several workers, and TsuJIOKA (1958) has also studied in the same subject in our laboratory. In connexion with his studies, the present experiment was attempted to clarify the relationship between this substance and a gut-stimu- 
lating component (component $\mathrm{T}$ ) which was produced on incubation with trypsin (ZETLER \& OHNEsorge, 1957).

As described in the previous section, gut-stimulating activity of the component $\mathrm{T}$ shows considerable resemblance to that of substance $\mathrm{P}$ in the pharmazological characteristics and chemical properties of both substances are also somewhat similar to each other. But distinct differences could be proved: contraction produced by the former is slower, not abolished by desensitization of the ileum strip to the latter, nor potentiated by LSD, but depressed more easily by high dose of pyribenzamin than the latter. The latter substance can not be extracted by hot ethanol-glacial acetic acid treatment which can be applied to isolate the former. Moreover, component $\mathrm{T}$ is inactivated neither by trypsin nor by $\mathrm{D}$ enzyme solution, while substance $\mathrm{P}$ is completely destroyed by trypsin and considerably inactivated by D-enzyme (TsuJiokA, 1958). It can be safely said, therefore, that component $\mathrm{T}$ is a gut-stimulating principle different from substance $\mathrm{P}$, though the former also appears to be of polypeptide nature as the latter.

Similarity of this component in its pharmacological and chemical properties to kinin compound such as plasma kinin is apparent from the results shown in the discrimination test and extraction procedure together with its formation by trypsin treatment. A possibility that this component is derived from contaminated plasma protein would be, as pointed out in the previous section, safely excluded. If plasmin contraction is produced by plasma kinin as supposed by TsuchIYA (1960), his finding, that the low dose of antihistaminic or EACA inhibits it, seems contradictory to ours on that of component $\mathrm{T}$. As shown in his results, inhibitory effect of EACA is most powerful when added to plasmin mixture prior to incubation and so it would be chiefly attributed to inhibition of the formation of an active kinin-like substance. A fact that activity of component $\mathrm{T}$ already formed is barely affected by EACA is, therefore, not so unexpected and unreasonable one. Difference in susceptibility to antihistaminic between plasmin contraction and that of component $\mathrm{T}$ is difficult to explain at the present stage, if both substances are kinin compounds and similar to each other.

Since the unboiled crude extract of dorsal root or whole brain (D-enzyme solution) provides component $\mathrm{T}$ by incubating with a-extract, it might be said that the nervous tissues, especially dorsal spinal cord themselves are capable of producing such an active principle. A fact that much longer incubation time was required for D-enzyme solution than for trypsin is probably attributable to lack of optimal conditions proper to the former as well as to insufficient amount of enzyme or enzymes under our experimental conditions. Physiological role of component $\mathrm{T}$ forming power in the nervous tissues remains still unobvious. These enzymes may be merely proteolytic ones common with various tissues and have no specific significance.

It seems worthy to note here, however, that the higher the content of sub- 
stance $\mathrm{P}$ in the tissue extract, the more component $\mathrm{T}$ is obtained on incubation with trypsin, a fact which suggests that distribution of precursor of component $\mathrm{T}$ runs parallel with that of substance $\mathrm{P}$. Applying the fractional centrifugation method of WhitTaKeR (1959), it was proved in our laboratory that his fraction of synaptic vesicles of bovine or guinea-pig's ventral cord contains large amount of ACh but small amount of substance P, while that of dorsal cord gives high content of SP, low ACh, its mitochondrial and microsomal fractions having only low activity. Moreover, in preliminary observations, the fraction of synaptic vesicles of dorsal cord was found to give CT activity higher than other fractions on incubation with trypsin (KATAOKA, unpublished). These findings seem to suggest that there exist some correlations of a precursor or precursors of component $\mathrm{T}$ to substance $\mathrm{P}$. It should be said at present, however, that not only such correlations but also physiological significance of component $\mathrm{T}$ or of CTforming activity found in the neuronal tissues are far from established, only an apparent fact being that component $\mathrm{T}$ is neither identical with nor derived from substance $\mathbf{P}$ and that the former is a kinin-like substance in its chemical and pharmacological properties, though a possibility of both principles being originated from the same substance seems to be not absolutely excluded.

\section{SUMMARY}

1. Bovine dorsal root, dorsal half of its spinal cord or guinea-pig's whole brain was extracted with about $70 \%$ ethanol at room temperature. When the extract was incubated with trypsin after concentrated in vacuo, substance P (SP) present in the original extract was destroyed but gut-stimulating activity apparently still remains, which could be ascribed to a new component (CT).

2. CT could be extracted by the procedure quite similar to RochA e SiLVA's extraction method of crude bradykinin and seemed to be of polypeptide nature.

3. The gut-stimulating activity of CT on guinea-pig ileum was barely affected by atropine, tryptamine, cocain, tetramethylammonium, hexamethonium, morphin, GABA and $\varepsilon$-amino-n-caproic acid and so resembles to that of SP. But contraction produced by the former is slower, not abolished by previous administration of SP, nor potentiated by LSD, but depressed by high dose of pyribenzamine.

4. Using guinea-pig's ileum, hen's rectal caeceum, and rat's uterus and colon, it was proved that action of CT is rather similar to that of plasma kinin and different from that of substance $\mathrm{P}$.

5. It was found that the higher the SP content of the tissue, the more CT was obtained on incubation with trypsin, dorsal spinal cord and small intestine giving higher CT activity, skeletal muscle and ventral cord lower one, 


\section{REFERANCES}

1) Andrades, S. and Rocha e Silva, M. (1957). Purification of bradykinin by ion-exchange chromatography. Biochem. J. 64: 701-704.

2) Euler, U. S. v. (1942). Herstellung und Eigenschaften von Substanz P. Acta Physiol. Scand. 4: 373-375.

3) Gaddum, J. H. (1955). Polypeptides which stimulate plain muscle, Livingston, Edinburgh \& London.

4) Gomes, F. P. (1955). A slow contracting substance in normal human urin. Brit. J. Pharmacol. 10: 200-207.

5) HoBbiger, F. (1958). Antagonism by $\gamma$-aminobutyric acid on the isolated mammalian ileum. J. Physiol. 142: 143-164.

6) Inouye, A., Fukuya, M., AND Tsujoka, T. (1960). Studies on the effects of $\gamma$-aminobutyric acid on the isolated guinea-pig ileum. Jap. J. Physiol. 10: 167-182.

7) LEWIS, G. P. (1958). Formation of plasma kinins by plasmin. J. Physiol. 140: 285-300.

8) Pernow, B. (1953). Studies on substance P, purification, occurrence and biological actions. Acta Physiol. Scand. 29, Suppl. 105: 1-86.

9) Pernow, B. And Rocha e Silva, M. (1955). A comparative study of bradykinin and substance P. Acta Physiol. Scand. 34: 59-66.

10) Rocha e Stlva, M. (1940) Beiträge zur Pharmakologie des Trypsins. Arch. exper. Path. Pharmakol. 194: 335-361.

11) Rocha e Silva, M., Beralde, W. T. and Rosenfeld, G. (1949). Bradykinin, a hypotensive and smooth muscle stimulating factor released from plasma globulin by snake venom and by trypsin. Amer. J. Physiol. 156: 261-273.

12) Tsuchiya, K. (1960). Studies on some inhibitory agents to the contraction of isolated intestine. II. On the contraction of guinea-pig ileum produced with plasmin. Kobe $J$. Med. Sci. 6: $53-59$.

13) Tsujioka, T. (1958). Studies on substance $\mathrm{P}$ in nervous tissue. Dissertation, Kyoto University School of Medicine.

14) Umrath, K. and H. F. Hellauer, (1948). Das Vorkommen der sensiblen Substanz und von Aktionssubstanzen abbauenden Fermenten. Pflüger's Arch. 280: 737-740.

15) UmRath, K. (1953). Ueber die fermentative Verwandlung von Substanz P aus sensible Neuronen in die Erregungssubstanz der sensiblen Nerven. Pflüger Arch. 258: 230-242.

16) WhitTAKER, V. P. (1959). The isolation and characterization of acetylcholine-containing particles from brain. Biochem. J. 72: 694-706.

17) ZetLer, G. AND OhNesorge, G. (1957). Die Substanz P-konzentration im Gehirn bei verschiedenen Funktionszustand des Zentral-nervensystems. Arch. exper. Path. Pharmakol. 231: $199-210$. 